\title{
EDITORIAL \\ Compassion as Caring in Crisis: Reflections of an Educator
}

https://doi.org/10.37719/jhcs.2020.v2i1.e001

The world is currently in crisis due to Covid-19 pandemic. People are anxious, most are grieving for the loss of a loved one or the loss of the freedom they once had. The unpredictable and chaotic nature of this pandemic is affecting not only the physical health of everyone but also their mental wellbeing. This is not at all a normal context or an ordinary time and this is the very same backdrop of our learners during a crisis situation.

The uncertainty of the current moment brings forth a surreal sense of existence as the people try to scout for meaning of what it is happening and what could happen in the near future. The Covid-19 virus cuts across racial, social, and economic boundaries. It knows no master. It respects no culture. Everyone is affected. Within this unpredictable and uncertain time, educators' expression of caring should reflect communal compassion rather than personal competence

The pandemic has exposed the many ills of societal inequalities, realities that many may have considered as normal. These further magnify the scarcity of resources and people's access to basic necessities. Because of these, some learners may find it difficult to make sense of the current situation. While others may show resilience, some may not. With these conditions from the ground, learners may find focusing on the task of learning burdensome and difficult. To require too much unnecessary demands from the learners at this time of chaos, whatever intent the educators may have, is totally uncalled for. For some people, the anxiety for a future that is unknown and unsure is as paralyzing as the thought of dying itself. To label learners as lazy because of the decline of their academic output within the crisis situation is gravely uncaring. Haphazard placing labels on learners only invalidate their personal pain and hidden suffering. Within the context of a crisis situation, educators must err on the safe side and assume that all learners are suffering regardless of their backgrounds.

It is not to say that learning should stop during this crisis but educators must be more reflective of the learners' circumstances. Their health and wellness are far more important than tasks that need to be accomplished. The submission of academic requirements is not an assurance that learning had indeed happen, more so during crisis situations. Compliance to the tasks does not necessarily translate to learning. In crisis moments, completion of academic requirements may at best be a reflection of forced obedience to rules rather than an evidence of 
achievement of any intended learning outcomes. This is what Roach described as competence without compassion; brutal and inhumane. Even with the best intention, educators may easily forget that in times of crisis, most learners are simply collecting information and not translating them into knowledge nor into wisdom.

During crisis like this, educators should be a living embodiment of caring. Knowing the person that is our learners and their unique context is the first step in this process. Embracing the sense of unknowingness is one of the bases of the process of knowing persons. The mastery of an educator in their field of expertise does not equate to the knowledge of their learners' personhood and context. Educators must be open to possibilities and be humble before opportunities of knowing. This is the path of empathy. To assume that all learners have the same context and to compare their experiences with ours is both insensitive and apathetic.

The educator's authentic presence with the learners during difficult situation is seen by most as caring. The genuine presence of another person during crisis moments is one of the most potent drugs of humanity. It instills hope in times where it seems to be lacking and meaning when there seems to be none. The professional boundaries some educators build around their interaction and presence with their learners needs to be modified. In a crisis situation, learners are seeking for the full presence of a person, not the academic guidance of an educator. The way towards this authentic presence is mindfulness. At times of crisis, educators must be mindful of the present moment and not fixated on an ambivalent future. Learners at this point are not focused on an unsure future but are enclosed within the chaotic present. Mindful educators will embrace the role of a companion and assist the learner make sense of the current situations rather than assume the role of a manger whose main aim is to keep the learner on track towards their educational goal. The prelude to fully living is basic existence.

In times of crisis, it is not enough that educators offer condolences and prayers then continue bombarding the learners with requirements. What learners need is not the assurance that things will be better soon but the certainty that another person will be with them when they feel uncertain. This is the sense of mediacy, of being authentically present when the other person needs us the most.

This pandemic and the series of crisis situations it brings reminds us that within these moments, the most appropriate and relevant expression of caring is the language of compassion. The sense of communal hope amidst the looming feeling of hopelessness during crisis moments can only be developed through the language of compassion. Empathy, authentic presence and mediacy are voices of this language. The best method to shape learners is to be the living example of the outcomes you want to achieve. In times like these, the best way to teach compassion is to live and speak its language.

Lest we forget, we are human beings first, educators second. At the end of this pandemic, educators will not be remembered by their competence but by their compassion. Educators are 
immortalized not only by fellow educators but by learners whose lives they have touched. Whenever there is doubt as to what course of action should be taken, it is wise to always choose the path laden with compassion. In times like these, educators need not be very brilliant, just compassionate.

As with all things, this crisis too shall come to pass. As Percy Shelley once said, "If winter comes, can spring be far behind?"

\section{References}

Roach, M.S. (2002). Caring, the Human Mode of Being: A Blueprint for the Health Professions, 2nd revised ed., Ottawa: Canadian Hospital Association.

Shelley, P. B. (2016). Ode to the West Wind. Journal of Singing, 73(1), 112.

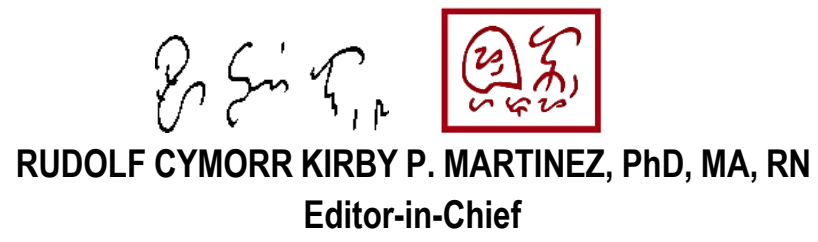

